\title{
Brief Discussions of a Draw of American Universal Education on Chinese Postgraduate Teaching Methods
}

\author{
Zhengminqing $\mathrm{Li}^{1}$, Lina Wang ${ }^{2}$ and Rupeng $\mathrm{Zhu}^{1}$ \\ ${ }^{1}$ College of Mechanical and Electrical Engineering, Nanjing University of Aeronautics and Astronautics, 210016 Nanjing \\ Jiangsu, China \\ ${ }^{2}$ Department of Art Design and Construction Engineering, Zhengde Polytechnic College, 211106 Nanjing Jiangsu, China
}

\begin{abstract}
Initiated by International Friendships Inc.(IFI) in Cincinnati, that is a Christian community organization, the authors participated in a universal education activity, called "History Museum", organized by the local people in Kentucky State of U.S.A. In the activity, the authors grasped some characteristics of American universal education and reflected some problems of the professional foundation teaching of Chinese postgraduates, especially of Chinese engineering postgraduates. Based on the above thinking, some suggestions of the teaching methods for the professional foundation courses of Chinese postgraduates are proposed. Furthermore, the authors hope the proposed methods would be good for improving the postgraduate education in China.
\end{abstract}

Keywords. American universal education; postgraduate education; professional foundation teaching; educational and teaching innovation

\section{Introduction}

The teaching innovation of Chinese postgraduate education, especially in the professional foundation teaching for engineering postgraduates, is one of the essential components of the teaching reforms of Chinese education. Many educators in various educational areas, such as infant education, higher education, investigated methods of the educational innovation for Chinese education positively. For example, Wang Yan discussed the inspiration of the infant educational reform of New Zealand on the preschool education of China ${ }^{[1]}$. Zhao Yanli inspected several problems in the infant educational reform ${ }^{[2]}$. Li Peifang proposed some ideas and methods to improve the primary school education ${ }^{[3]}$. Zhou Hongxia studied the reform direction of the primary schools of Singapore ${ }^{[4]}$. Wang Lei checked some problems in the reform of the middle school education, and Yan Fei assessed the teaching methods of the middle school education in 21 st century $^{[5-6]}$. Liang Lin and Sun Xiaohui evaluated the reform and development of the higher education of Canada as well as Fan Xia proposed some alter methods of the higher education for adults ${ }^{[7-8]}$. Meng Cuihu studied the improvement of the domestic postgraduate education ${ }^{[9]}$.

In these researches, the scholars almost employed the transverse-parallel contrastive methods in the teaching reform of all kinds of the educations, which is comparing the advantages and drawbacks of the teaching of the foreign countries with those of China in the same educa- tional area, to introduce the advanced teaching ideas and methods into China. However, they ignored the longitude-vertical contrastive teaching methods of the education, which probably would be a good explore for the educations due to the same inherent characters among the infant education, the elementary education, the professional education and the higher education. Thus, in this study, a draw of American universal education on Chinese postgraduate teaching methods is discussed. American universal education occupied the extreme features, the effective methods and the excellent experiences. Meanwhile, there are many similar characteristics between in Chinese postgraduate teaching, especially in the professional foundation teaching of engineering postgraduates, and in American universal education. Therefore, in this article, the features of American universal education are studied, based on the American universal education activity "History Museum" organized by IFI in Cincinnati. The problems of the professional foundation teaching for Chinese post-graduates, especially for engineering postgraduates, are discussed. Furthermore, some suggestions of the teaching methods by drawing on the excellent experiences of American universal education, which would be beneficial to improve of the professional foundation teaching, are proposed.

\section{Characteristics of American universal education}


The universal education activity "History Museum", which the authors participated in, was voluntarily organized by the local people with the local historical knowledge of Kentucky State.

The purpose of this "History Museum" was to let the American young generation know about the past and the history of U.S.A, and increase the passion and the recognition of the homeland. In the activity, the learning background mainly represented the living of the local white people, who lived in 18 th century.

Firstly, in the long classroom learning of the background, there was not only a teacher, but also several teachers, who were familiar with the relevant background respectively. In addition, they introduced the historical knowledge vividly.

Secondly, after the classroom learning of the historical background, the organizers of the activity guided the participators to enter a real condition described as the early learning. The self-participation of the learners would deepen the knowledge, who studied before.

Finally, in the activity, the participators could conduct a practical operation in the guidance of the organizers, which was one of their favorites, and sell their achievements publicly to increase the interest and the confidence of their learning.

Based on the analysis of the History Museum, the characteristics of American universal education can be divided into the following 3 points:

1) A teaching team for a course: that means not just one teacher to teach all of the knowledge points of a course. Otherwise, several teachers, who had their own special teaching area separately, composed a teaching team to teach a course in a classroom.

2) Teaching visualization: a true environment of the application of the learning is specially focused on by teachers in the classroom teaching since it could improve the understanding of the knowledge for the learning of students.

3) Teaching field: Students could not only reinforce their knowledge, but also increase the interests and the confidence of studies by their own participation.

\section{Teaching problems of Chinese post- graduates}

Currently, teaching problems of Chinese postgraduates, especially in the professional foundation teaching of engineering postgraduates, can be summarized as three features, they are a wide scope of the knowledge, insufficient class hours and dull theories in a course. Therefore, it made students to find the interests in professional foundation learning difficultly and accept the knowledge passively, which weakened the grasping of the professional foundation knowledge and destroyed the study interest in professional foundation courses.

In our opinion, the above teaching problems were caused by the teaching methods for postgraduates in universities. The reasons are as follows:

1) Non-professional teaching. A postgraduate course, especially of the professional foundation learning of engineering postgraduates, was always conducted by only one teacher. If the teacher had a research title such as the associate professor or the professor, the course opened by the teacher would be considered as a course conducted by an expert. However, it is well known that each university in China is not only an educational institution, but a researching organization as well. As for the research, every researcher almost had a study area obviously and only deepened one point of his research which could improve his professional research level. Otherwise, as for the teaching, especially in the professional foundation courses, all of the key learning points of a course, which may be basic, need be expressed clearly to students by a teacher, who must understand all of the key points that is not a piece of cake for any teachers. Therefore, comparing the requirements of the research with those of the teaching for engineering postgraduates, the teachers, who had the research title, are only the experts in their study area, and maybe are not the experts of the teaching, especially in the professional foundation learning of engineering postgraduates.

2) Non vivid teaching. In a course of postgraduates, especially in a professional foundation course, as for a teacher, the purpose of the teaching was made students to understand the key points of the learning. Moreover, the professional foundation learning of engineering postgraduates has been the logical and theoretical characteristics strongly. Thus, under the limited teaching hours, the teachers almost had to employ the didactic teaching method, which is not vivid and impressive.

3) Non practice teaching. Many professional foundation courses for engineering postgraduates only are thought as the extensions of those in the undergraduate stage. Therefore, the practices of these courses, which could improve to understand the knowledge of the learning, almost are ignored and the evaluation of the learning is determined by the reports or the easy tests of students.

\section{Enlightenment of American universal education for Chinese postgraduate teaching}

Although American universal education is not the same with Chinese postgraduate education based on the educational areas, the teaching methods of American universal education would be good for improving the teaching level of Chinese postgraduates by the above analysis of the advantages of American universal education and the problems of Chinese postgraduate education. Thus, in the study, three suggestions of the teaching methods for Chinese postgraduate education are proposed. There are in follows:

1) Compose a professional teaching team for a course. One teacher can be substituted by a teaching team, which consist of several teachers who are the experts in their relevant teaching areas, for a course.

2) Increasing the scenario teaching. The scenario teaching, such as teaching in lab, should be in- 
creased into the classroom teaching because the environment of the learning could adjust the study emotion of students to improve their learning interest.

3) Project assessment for a course. The final test of a course should be combined with a practical work or a research project in order to let students use the knowledge that they had learned as well as a traditional report of the assessment for a student should be replaced by the practical achievements.

\section{Conclusions}

The characteristics of American universal education are summarized by participating in American universal education called "History Museum" in Kentucky State and the problems of the teaching of Chinese post-graduates, especially in the professional foundation teaching of engineering postgraduates in China, are discussed. Comparing American universal education with Chinese postgraduate education, that is the longitude-vertical teaching comparison because they do not belong to the same educational area, three suggestions of the teaching methods for improving the teaching of Chinese postgraduate education are proposed.

\section{Acknowledgment}

This paper is supported by China Scholarship Council (201206835011) and Jiangsu University Philosophy and Social Sciences Foundation (2013SJDFDY099).

\section{References}

1. Wang Yan. Several enlightenments of the preschooleducation reform of New Zealand on the preschool education of China [J]. Education Forum, 2012, 38B: 261-263.

2. Zhao Yanli. Brief discussion on several problems of the preschool education innovation [J]. Education for Chinese After-school (Theory), 2012, 4:151.

3. Li Peifang. Methods and enlightenments of the primary-education reform [J]. Henan Science \& Technology, 2013, 6:266-267.

4. Zhou Hongxia. Founding for the future study- primary-education innovation of Singapore [J]. Elementary \& Secondary Schooling Abroad, 2009, 6:54-57.

5. Wang Lei. Some discussions on the middle-school educational innovation in China [J]. New Campus: Theoretical Version, 2012, 3:66.

6. Yan Fei. Brief discussions on the middle school education reform in 21th Century [J]. Scientific Technology Collection, 2009, 6:56.

7. Liang Lin and Sun Xiaoxia. The reform and the development of the higher Education innovation of Canada by the International view [J]. Journal of Educational Institute of Jilin Province, 2013, 29(7):5859.

8. Fan Xia. The development strategies of the adult higher education in China [J]. Jiangsu Higher Education, 2010, 1:151.

9. Meng Cuihu. Discussions on the postgraduate education innovation of China [J]. Jiangsu Higher Education, 2007, 4:152. 